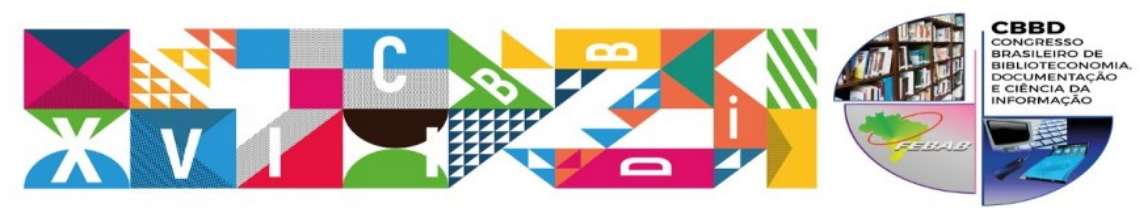

XXVII CONGRESSO BRASILEIRO DE BIBLIOTECONOMIA, DOCUMENTAÇÃO E CIÊNCIA DA INFORMAÇÃO

TEMA CENTral: Objetivos para o Desenvolvimento Sustentável das Naçōes Unidas:
como as bibliotecas podem contribuir com a implementação da Agenda 2030

Eixo 3 - Gestão de Bibliotecas

\title{
SERVIÇO VIRTUAL: o WhatsApp como meio de comunicação na Biblioteca da Saúde da Universidade Santa Cecília - Santos/SP
}

\author{
Cibele Fernandes de Oliveira \\ Coordenadora da Biblioteca de Saúde \\ da Universidade Santa Cecília. Mestre \\ em Ensino em Ciências da Saúde pela \\ Universidade Federal de São Paulo. \\ E-mail: cibele@unisanta.br
}

\section{RESUMO}

Adaptando-se às mudanças tecnológicas, a Biblioteca da Saúde da Universidade Santa Cecília - Santos/SP decidiu implementar o serviço de WhatsApp como um canal de comunicação mais dinâmico com os usuários. É por meio do WhatsApp que divulgamos nossos serviços e atividades culturais, respondemos sobre dúvidas, realizamos cobrança dos materiais em atraso e, como carro chefe: avisamos quando a obra reservada pelo usuário se encontra disponível na Biblioteca. Atualmente o gerenciamento é realizado por dois funcionários que, diariamente, estão on-line no horário de funcionamento da Biblioteca. 0 serviço é realizado somente através das listas de transmissão garantindo a confidencialidade dos demais números de celulares. A inclusão do usuário no WhatsApp é realizada somente após a autorização do usuário com o preenchimento de uma ficha cadastral no balcão de atendimento. A popularização deste serviço aproximou os usuários da Biblioteca, afinal, em poucos minutos, enviamos uma resposta às suas perguntas, além de eles poderem acompanhar o que acontece no setor, como a aquisição de novos títulos e as atividades culturais. Como extensão do projeto e a pedido dos próprios usuários, no próximo semestre, iniciaremos o serviço de WhatsApp com um novo número para a outra Biblioteca da Instituição.

Palavras-chave: Serviço virtual. Biblioteca universitária. WhatsApp.

VIRTUAL SERVICE: WhatsApp as a means of communication in the Health Library of Santa Cecília University - Santos/SP

\section{ABSTRACT}

Adapting to technological changes, the Health Library of the Santa Cecília University - Santos / SP decided to 


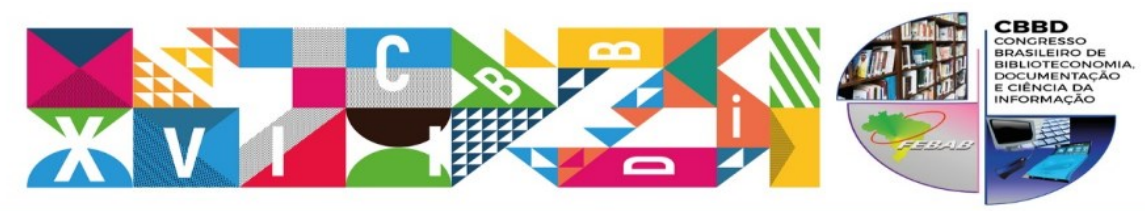

XXVII CONGRESSO BRASILEIRO DE BIBLIOTECONOMIA,

DOCUMENTAÇÃO E CIÊNCIA DA INFORMAÇÃO

TEMA CENIral: Objetivos para o Desenvolvimento Sustentável das Naçōes Unidas:

implement the WhatsApp service as a more dynamic channel of communication with users. It is through WhatsApp that we publish our services and cultural activities, respond to questions, remind users of late material devolution and, as the main service/flagship service/core service: we will let user know when their reserved material is available in the Library. Currently the management is carried out by two employees who are online every day during the Library's opening hours. The service is only conduted through the transmission lists, ensuring confidentiality of other cell phone numbers. The inclusion of a user in the Library WhatsApp Service is made only after the user's authorization by filling a registration form at the service desk. The popularization of this service brought users to the Library, after all, in a matter of minutes, we answer to their questions and make them able to follow what happens in the sector, such as the acquisition of new titles and cultural activities news. As an extension of the project and at the request of the users themselves, in the next semester, we will start the WhatsApp service with a new number to the other Library of the Institution.

Keywords: Virtual service. University library. WhatsApp.

\section{INTRODUÇÃo}

As tecnologias de informação e comunicação (TICs) transformaram os serviços e produtos ofertados pelas bibliotecas. De acordo com Ribeiro (2012, p. 41) “as bibliotecas ao longo do tempo foram celeiros de novas tecnologias, passando do pergaminho ao CDROM, das fichas perfuradas ao catálogo on-line, das estantes em madeira às bases e bancos de dados", sempre buscando se adaptarem às novas tendências de modo proativo.

Ranganathan (2009) já explicitava essa dinâmica, através da quinta lei da biblioteconomia: "a biblioteca é um organismo vivo", ou seja, as mudanças são necessárias, de tempos em tempos. Assim, as TICs podem ser empregadas como uma estratégia para atender às novas necessidades dos usuários nas bibliotecas.

Essas mudanças ainda estão em aberto e se transformam à medida que a própria internet redefine seu escopo e alcance. Parece que a internet pode ser colocada como um marco civilizatório: a vida antes e depois da 


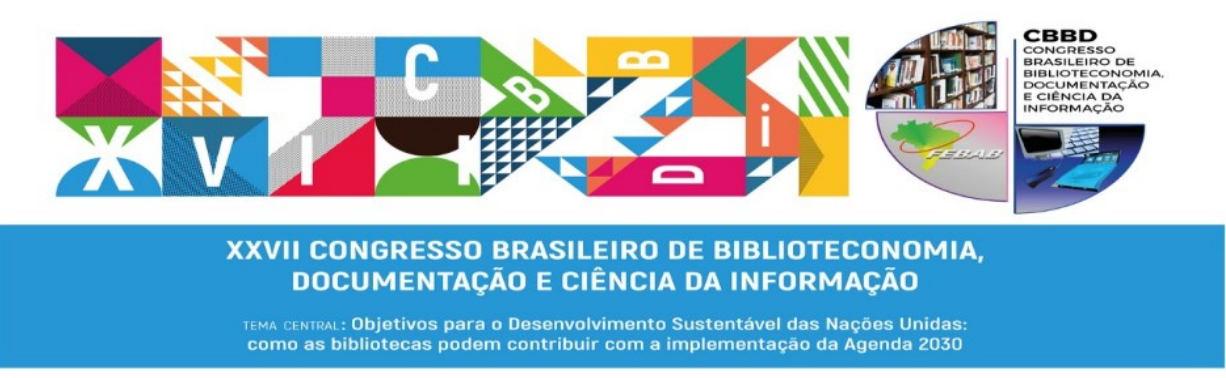

internet, pois ela tem criado expectativas elevadas de mudanças, algumas até revolucionárias (PINHO, 2014, p. 98).

Kaieski, Grings e Fetter (2015, p. 4) relatam que "a popularização do acesso à internet com banda larga propulsionou as novas tecnologias na direção da integração, da instantaneidade da comunicação audiovisual e interativa". Nesse âmbito, surge o WhatsApp.

O WhatsApp é um aplicativo de mensagens instantâneas para dispositivos móveis, tablets e PCs. Foi criado em 2009 por Jan Koum e Brian Acton e atualmente mais de um bilhão de pessoas, em mais de 180 países, fazem uso deste aplicativo para se comunicar com seus familiares e amigos. Suas funcionalidades são o envio de arquivos de mídia, tais como: fotos, vídeos, documentos, compartilhamento de localização e textos e as chamadas de voz (WHATSAPP, 2017).

É inquestionável que o WhatsApp se popularizou muito nos últimos anos, tornando-se um canal de comunicação valoroso na vida pessoal e profissional das pessoas. Hoje em dia, muitos serviços são marcados via WhatsApp devido ao baixo custo deste aplicativo, afinal para sua utilização é necessário somente uma conexão com a internet (FABREGA; OLLE; CICRES, 2016).

Segundo Muriel-Torrado, et al. (2016, p. 15), o WhatsApp é um campo a ser explorado pelas bibliotecas brasileiras, afinal "o atendimento através deste aplicativo pode nos ajudar a ficar mais perto dos nossos usuários e lhes oferecer os melhores serviços".

Nesse contexto, em 2014, a Biblioteca da Saúde da Universidade Santa Cecília Unisanta decidiu implementar o serviço de WhatsApp para estreitar a comunicação entre Biblioteca e usuário. Inicialmente a proposta foi sugerida para solucionar um contratempo do serviço de reserva.

O serviço de reserva não estava alcançando seu real objetivo, porque os livros mais reservados quase não estavam sendo retirados da Biblioteca, isto porque o usuário era avisado via e-mail (mensagem automática do sistema Biblioteca Nativa - BNWEB) de que o livro reservado estava disponível e de que teria 24 horas para buscá-lo, entretanto, muitos usuários não checavam seus e-mails perdendo suas reservas. Com isso, os livros 


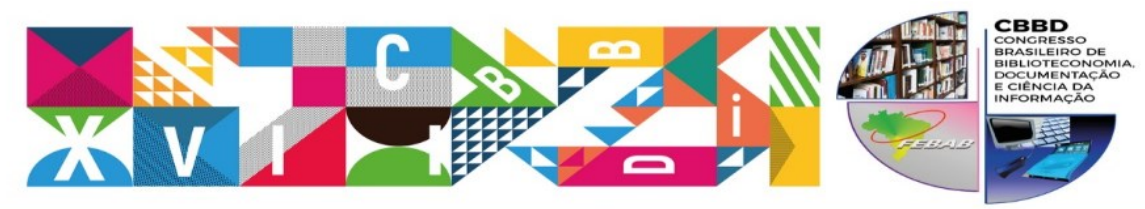

XXVII CONGRESSO BRASILEIRO DE BIBLIOTECONOMIA,

DOCUMENTAÇÃO E CIÊNCIA DA INFORMAÇÃO

TEMA CENTral: Objetivos para o Desenvolvimento Sustentável das Naçōes Unidas:

mais reservados ficavam parados no balcão, apenas aguardando o próximo da lista que, na maioria das vezes, também perdia o prazo.

Com isso, começamos a pensar em alguma ferramenta que pudesse resolver este impasse e que, ao mesmo tempo, fosse de baixo custo para sua implementação já que a Biblioteca não dispunha de verba.

Na época já tínhamos Wi-fi na Biblioteca e uma das funcionárias do setor havia trocado seu celular recentemente doando seu antigo aparelho para o setor. Foi assim que começamos a utilizar o aplicativo WhatsApp na Biblioteca.

Inicialmente implementamos o serviço de avisar quando o livro reservado estava disponível na Biblioteca e, em pouco tempo, percebemos que o serviço de reserva estava cumprindo seu papel. Posteriormente, começamos a utilizá-lo para enviar comunicados da Biblioteca (alterações de horário, férias, bloqueio da renovação on-line, compra de livros, etc.), divulgação das atividades culturais (saraus, conexão cultural, feira de livros, etc.), cobrança dos materiais em atraso e resolução de dúvidas (renovação, reserva online, etc.) por parte dos usuários.

\section{BIBLIOTECAS UNIVERSITÁRIAS E ATENDIMENTO ON-LINE}

As bibliotecas universitárias ou acadêmicas são aquelas mantidas por instituições de ensino superior e se caracterizam por assumirem a responsabilidade de oferecer suporte informacional a toda a comunidade acadêmica da instituição, entendida como o corpo docente, discente e pessoal técnico-administrativo (CUNHA; CAVALCANTI, 2008).

Ainda de acordo com Contardi (2011, p. 18), “as bibliotecas universitárias continuam sendo a estrutura de apoio essencial para que as Universidades cumpram seus objetivos de formação e investigação". Silveira complementa dizendo que (2009, p. 127) é função das bibliotecas universitárias "subsidiar as atividades de ensino, de pesquisa e de extensão desenvolvidas nas universidades, mediante a provisão de recursos informacionais seletivos, diversificados e organizados".

Em relação ao seu desenvolvimento, Job (2006) relata que grande parte dos esforços foram motivados pelos próprios bibliotecários, pois estes articularam uma 


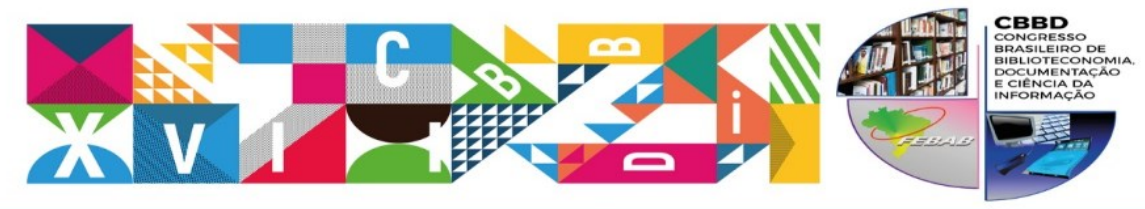

XXVII CONGRESSO BRASILEIRO DE BIBLIOTECONOMIA,

DOCUMENTAÇÃO E CIÊNCIA DA INFORMAÇÃO

TEMA CENIral: Objetivos para o Desenvolvimento Sustentável das Naçōes Unidas:
como as bibliotecas podem contribuir com a implementaçāo da Agenda 2030

cooperação entre sistemas e redes de informação não só no interior das universidades, mas também as conectando a nível nacional e internacional. Além de favorecer o acesso informacional, a biblioteca universitária, assim concebida, também propõe o desenvolvimento das possíveis potencialidades dos diversos agentes sociais que estão ali presentes. Isso se dá pela capacitação das pessoas e pela possibilidade de ampliar os seus horizontes teórico-metodológicos ao fortalecer suas ideias.

De acordo com Medeiros et al. (2016, p. 2) "muitas bibliotecas ao redor do mundo têm adotado o conceito de rede social como um meio de prestação de seus serviços de informação on-line para os usuários”, proporcionando, assim, uma relação mais próxima com os usuários e, ao mesmo tempo, levando os serviços prestados pelas bibliotecas de forma virtual.

Por isso, o Sistema Integrado de Biblioteca da Universidade Santa Cecília, na cidade de Santos/SP (SIBi), composto por três bibliotecas: Central (engenharias, arquitetura, administração, sistemas de informação e comunicação), Direito (ciências jurídicas) e Saúde (ciências biológicas e saúde), decidiu implantar o serviço de WhatsApp na Biblioteca da Saúde como um novo modo de atendimento on-line.

\section{RELATO DA EXPERIÊNCIA}

No ano de 2014 iniciamos, na Biblioteca da Saúde, o WhatsApp como um serviço de alerta aos usuários que desejavam saber se o material reservado por eles estava disponível na Biblioteca para seu empréstimo.

Para sua implantação, no início, recebemos a doação de um celular com um chip pré-pago de uma funcionária do setor que na época iria descartá-lo. 0 acesso à internet foi através da própria rede Wi-Fi que a Biblioteca dispõe.

Em relação ao cadastro dos usuários no aparelho, apenas o realizamos após a sua autorização e preenchimento de uma ficha cadastral (curso, RA, nome e celular) no balcão de empréstimo. Deve-se ressaltar que este serviço não é a criação de grupos da Biblioteca, ou seja, cada mensagem enviada por nós é pessoal a cada usuário. Para tanto, utilizamos 

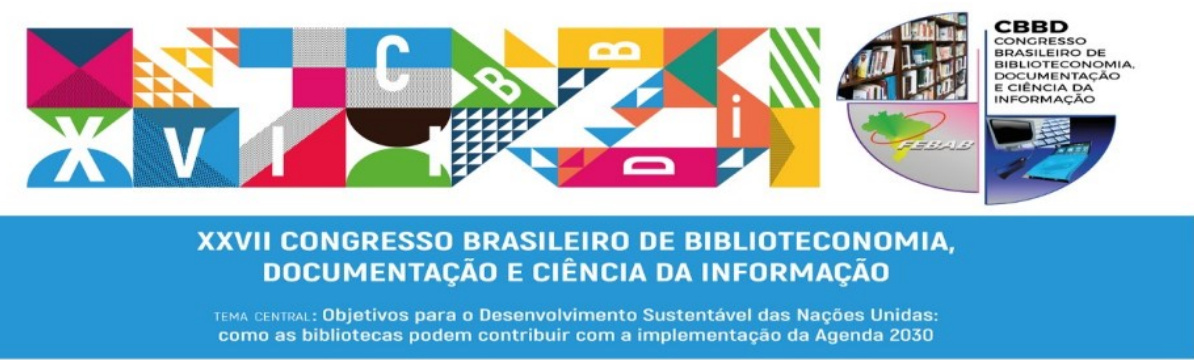

a lista de transmissão no envio de mensagens, assim preservamos a privacidade dos números dos demais usuários.

Quadro 1 -Ficha cadastral para participar do WhatsApp

\begin{tabular}{|c|c|}
\hline Curso: & \\
\hline RA: & \\
\hline Nome: & \\
\hline Celular: & ( ) 9 \\
\hline
\end{tabular}

Fonte: elaboração própria

Para a organização das listas no aparelho celular, segmentamos os usuários por categorias e utilizamos a abreviatura do curso, número do RA e data da inclusão. Os quadros a seguir exemplificam estes cadastros.

Quadro 2 - Cadastro dos usuários no aparelho

\begin{tabular}{|c|c|}
\hline Aluno & Funcionário \\
\hline$\underline{\text { Sigla do Curso }}+\mathrm{RA}+$ Ano da inclusão & Sigla de Funcionário $(\mathrm{Fu})+$ Nome $+\underline{\text { Sigla do Setor }}$ \\
\hline & Ex: \\
\hline Biologia: Bi 1234562017 & Fu Daiane TV \\
\hline Odontologia: $\underline{\mathrm{Od} 2} 1234562017$ & Fu Aninha DP \\
\hline Professor & Visitantes -Atividades Culturais \\
\hline$\underline{\text { Sigla do Curso }}+$ Nome e sobrenome & $\underline{\text { Sigla de Visitante }(V)}+$ Nome e sobrenome \\
\hline & \\
\hline Fisioterapia: Fi Rivaldo Novaes & V João da Silva \\
\hline Educação Física: EF Nicolau Teixeira & V Maria de Jesus \\
\hline
\end{tabular}

Fonte: elaboração própria 

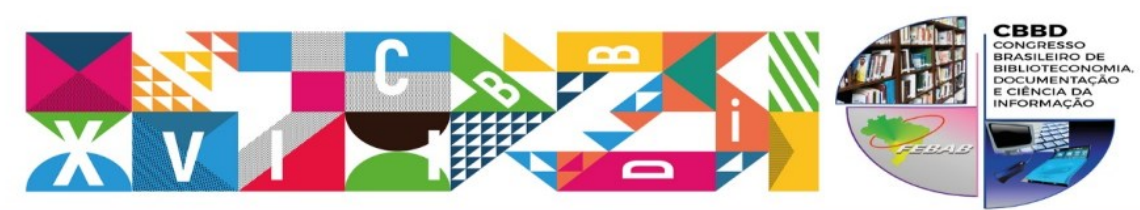

XXVII CONGRESSO BRASILEIRO DE BIBLIOTECONOMIA,

DOCUMENTAÇÃO E CIÊNCIA DA INFORMAÇÃO

TEMA CENRrRa: : Objetivos para o Desenvolvimento Sustentável das Naçōes Unidas:
como as bibliotecas podem contribuir com a implementaçăo da Agenda 2030

Quadro 3 - Lista de abreviatura

\begin{tabular}{|l|c|}
\hline Cursos de graduação & Abr. \\
\hline Biologia & Bi \\
\hline Educação Física & EF \\
\hline Farmácia & Fa \\
\hline Fisioterapia & Fi \\
\hline Odontologia & Od \\
\hline
\end{tabular}

Fonte: elaboração própria
Quadro 4 - Lista de abreviatura

\begin{tabular}{|l|c|}
\hline Cursos de Pós e Mestrado & Abr. \\
\hline Educação Física & PEF \\
\hline Farmácia & PFa \\
\hline Fisioterapia & PFi \\
\hline Odontologia & POd \\
\hline Mestrado em Ecologia & ME \\
\hline
\end{tabular}

Fonte: elaboração própria

Quadro 5 - Procedimentos de cadastro

\section{Observações importantes}

- Sempre adicionar o número com o DDD - EX.: (13)99345-6789;

- Adicionar um "W" ao lado do celular no cadastro do BNWeb para identificar que tem WhatsApp (informação útil para cobrança de atraso de livros);

- Adicionar um "N" ao lado do celular se o usuário não tiver o aplicativo ou se não quiser participar;

- Após adicionar o contato no celular e atualizar no BNWeb, dar "OK" na ficha de cadastral e escrever a data ao lado;

- Se o usuário se cadastrar diretamente (pelo seu próprio celular), solicitar seu RA e nome do curso.

$$
\text { Fonte: elaboração própria }
$$

Com essa organização, conseguimos direcionar, adequadamente, o que e para quem queremos enviar uma mensagem. A gestão desse aplicativo é realizada por 2 funcionários que trabalham em diferentes turnos (manhã/ tarde e tarde/noite), com isso, temos a cobertura do serviço das $8 \mathrm{~h}$ às $21 \mathrm{~h} 45$, de segunda a sexta-feira, e aos sábados, das 8 h às 11h45 (mesmo horário de atendimento da Biblioteca).

Para divulgação deste serviço, criamos cartazes com o nosso número (ver abaixo) e a cada início de semestre, em que recebemos os usuários para confirmação do cadastro na Biblioteca, explicamos sobre os benefícios deste serviço. 


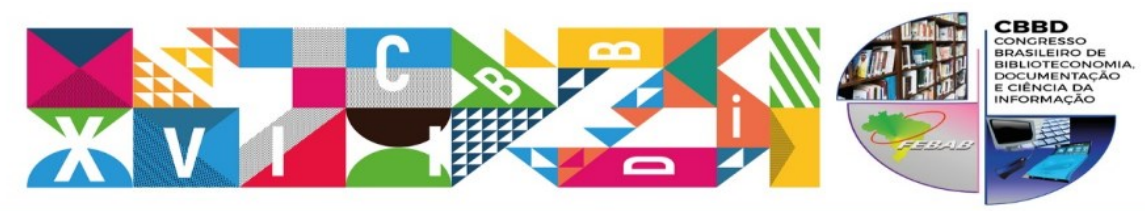

XXVII CONGRESSO BRASILEIRO DE BIBLIOTECONOMIA,

DOCUMENTAÇÃO E CIÊNCIA DA INFORMAÇÃO

TEMA CENTral: Objetivos para o Desenvolvimento Sustentável das Naçōes Unidas:
como as bibliotecas podem contribuir com a implementaçāo da Agenda 2030

Figura 1 - Cartaz de divulgação

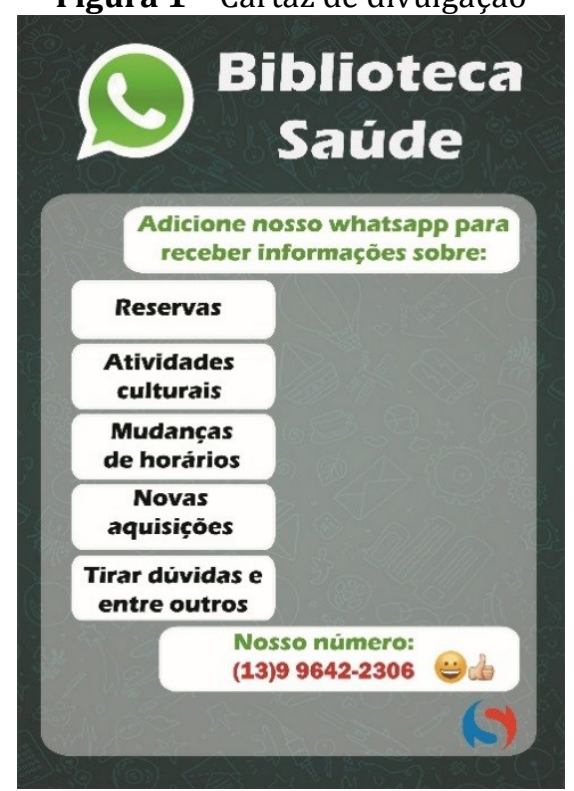

Fonte: elaboração própria

O serviço foi rapidamente aceito pelos usuários e em pouco tempo, solucionamos a problemática dos materiais em reserva. Devido ao sucesso, no mesmo ano, implementamos outros serviços pelo WhatsApp, tais como: comunicados da Biblioteca (alterações de horário, férias, bloqueio da renovação on-line, etc.), novas aquisições (enviamos fotos das capas dos livros adquiridos), divulgação das atividades culturais (saraus, conexão cultural, feira de livros, etc.), cobrança dos materiais em atraso e resolução de dúvidas (renovação, reserva on-line, etc.) por parte dos usuários. Em 2016 conseguimos adquirir um tablet para administrar este serviço, pois o celular não estava suportando tantos contatos, somado a dificuldade de digitação, afinal o aparelho era antigo.

Atualmente contamos com 808 usuários cadastrados, sendo 724 alunos, 32 professores, 25 funcionários e 27 visitantes. Neste primeiro semestre de 2017, recebemos 209 mensagens (dúvidas sobre renovações on-line, horário de funcionamento, multas, etc.) e enviamos 48 mensagens (divulgação das atividades culturais, informativos, aquisição de livros, etc.) para os grupos, além das mensagens do serviço de reserva e cobrança que, em média, foram mais de 300 mensagens. 


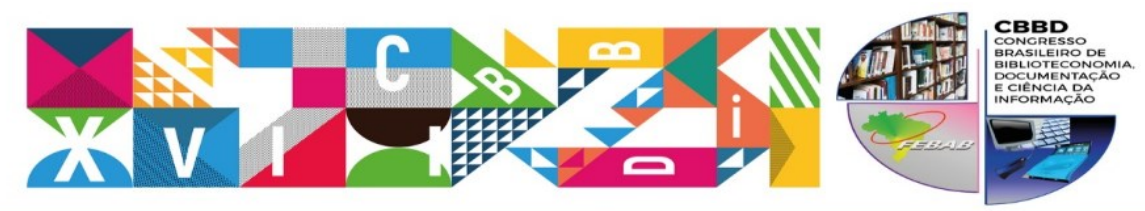

XXVII CONGRESSO BRASILEIRO DE BIBLIOTECONOMIA, DOCUMENTAÇÃO E CIÊNCIA DA INFORMAÇÃO

TEMA CENTRAL: Objetivos para o Desenvolvimento Sustentável das Naçōes Unidas:
como as bibliotecas podem contribuir com a implementação da Agenda 2030

\section{CONSIDERAÇÕES FINAIS}

Pode-se considerar que o uso do WhatsApp na Biblioteca da Saúde da Unisanta é uma experiência de sucesso e recomenda-se que outras bibliotecas o adotem.

Sabe-se que muitas bibliotecas no exterior se utilizam deste serviço, no entanto essa prática no Brasil ainda é bastante tímida, principalmente em relação ao uso no serviço de reserva e na própria comunicação com os usuários.

A pedido dos alunos, estamos ampliando este serviço com a adoção de um novo número de WhatsApp para a Biblioteca Central e Direito. Este serviço será implementado no segundo semestre de 2017.

Por último, mais uma vez, as palavras de Ranganathan (2009) se fazem presentes na lei "poupe o tempo do leitor", afinal, com esta ferramenta ficamos mais próximos de nossos usuários e conseguimos responder às suas dúvidas em questão de segundos.

\section{REFERÊNCIAS}

CONTARDI, S. Prácticas de las bibliotecas universitarias argentinas: reflexiones críticas en el contexto de la comunicación académica y sus representaciones en la web. Inf. Cult. Soc., n.24, p. 139-141, 2011. Disponível em: <http://www.scielo.org.ar/scielo.php?pid=S185117402011000100009\&script=sci arttext>. Acesso em: 02 abr. 2015.

CUNHA, M. B. da; CAVALCANTI, C. R. O. Dicionário de biblioteconomia e arquivologia. Brasília: Briquet de Lemos, 2008.

FABREGA, M. A.; OLLE R.B.; CICRES, A.M. WhatsApp: nou canal de comunicació a la Biblioteca de la Universitat de Girona. Rev. De biblioteconomia i documentació, n. 61, p. 105 - 117, 2016. Disponível em:

< https://dialnet.unirioja.es/servlet/articulo?codigo=5767633>. Acesso em: 30 jun. 2017.

KAIESKI, N.; GRINGS, J.A.; FETTER, S.A. Um estudo sobre as possibilidades pedagógicas de utilização do WhatsApp. Revista Novas Tecnologias na Educação. Porto Alegre, v. 13, n. 2, p. 110, 2015.

Disponível em: <http://seer.ufrgs.br/index.php/renote/article/view/61411/36314>. Acesso em: 02 jul. 2017.

JOB, I. A biblioteca universitária brasileira na sociedade global. In: CONGRESSO ONLINE OBSERVATÓRIO PARA A CIBERSOCIEDADE, 3, 2006, Cataluya. Anais...Cataluya: Observatorio para la sociedad, 2006. Disponível em:

$<$ http://www.cibersociedad.net/congres2006/gts/comunicacio.php?id=678\&llengua=po $>$. Acesso em: 02 abr. 2017. 


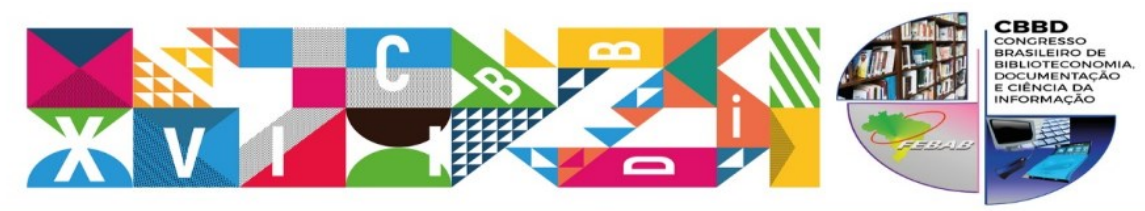

XXVII CONGRESSO BRASILEIRO DE BIBLIOTECONOMIA, DOCUMENTAÇÃO E CIÊNCIA DA INFORMAÇĀO

TEMA CENrRal: Objetivos para o Desenvolvimento Sustentável das Naçōes Unidas:
como as bibliotecas podem contribuir com a implementaçăo da Agenda 2030

MEDEIROS, S. A. et al. Webmarketing e o desenvolvimento de uma política de redes sociais: estudo de caso da Biblioteca Universitária a Universidade Federal de Lavras. In: SEMINÁRIO NACIONAL DE BIBLIOTECAS UNIVERSITÁRIAS, 19, 2016, Manaus. Anais...[S.l.], 2016. Disponível em: <http://periodicos.ufam.edu.br/anaissnbu/article/view/3293 >. Acesso em: 10 nov. 2017.

MURIEL-TORRADO, E. et al. Serviços on-line das bibliotecas universitárias brasileiras. In: ENCONTRO NACIONAL DE PESQUISA EM CIÊNCIA DA INFORMAÇÃO, 17, 2016, Salvador. Anais... Salvador: UFBA, 2016. Disponível em:

$<$ https://www.researchgate.net/publication/317540270 SERVICOS ON-

LINE DAS BIBLIOTECAS UNIVERSITARIAS BRASILEIRAS >. Acesso em: 14 nov. 2017.

PINHO, J. A.G. de. Sociedade da informação, capitalismo e sociedade civil: reflexões sobre política, internet e democracia na realidade Brasileira. Rev. adm. empres., São Paulo, v. 51, n. 1, p. 98106, 2011. Disponível em :<http://www.scielo.br/scielo.php?

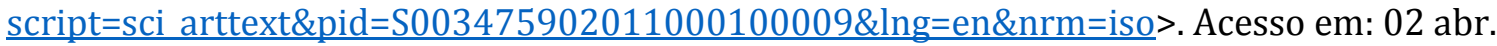
2017.

RANGANATHAN, S. R. As cinco leis da Biblioteconomia. Brasília, DF: Briquet de Lemos, 2009.

RIBEIRO, R. M. R. A tecnologia das informação e comunicação (TIC): fator condicionante da inovação em bibliotecas universitárias. Rev. Dig. Bibl. Ci. Inf., Campinas, v.9, n.2, p.41- 48, 2012. Disponível em: <www.sbu.unicamp.br/seer/ojs/index.php/sbu rci/index>. Acesso em: 02 jul. 2017.

SILVEIRA, J. G. Gestão de recursos humanos em bibliotecas universitárias: reflexões. Ciência da informação, Brasília, v. 38, n. 2, p. 126-141, 2009.

WHATSAPP. WhatsApp, 2017. Disponível em: <https://www.whatsapp.com/about/>. Acesso em: 30 jun. 2017. 